\title{
Screening microalgae isolated from urban storm- and wastewater systems as feedstock for biofuel
}

\author{
Rebecca Massimi ${ }^{1}$, Andrea E Kirkwood ${ }^{\text {Corresp. } 1}$ \\ ${ }^{1}$ Faculty of Science, University of Ontario Institute of Technology, Oshawa, Ontario, Canada \\ Corresponding Author: Andrea E Kirkwood \\ Email address: andrea.kirkwood@uoit.ca
}

Exploiting microalgae as feedstock for biofuel production is a growing field of research and application, but there remain challenges related to industrial viability and economic sustainability. A solution to the water requirements of industrial-scale production is the use of wastewater as a growth medium. Considering the variable quality and contaminant loads of wastewater, algal feedstock would need to have broad tolerance and resilience to fluctuating wastewater conditions during growth. As a first step in targeting strains for growth in wastewater, our study isolated microalgae from wastewater habitats, including urban stormwater-ponds and a municipal wastewater-treatment system, to assess growth, fatty acids and metal tolerance under standardized conditions. Stormwater ponds in particular have widely fluctuating conditions and metal loads, so microalgae from this type of environment may have desirable traits for growth in wastewater. Forty-three algal strains were isolated in total, including several strains from natural habitats. All strains, with the exception of one cyanobacterial strain, are members of the Chlorophyta, including several taxa commonly targeted for biofuel production. Isolates were identified using taxonomic and 18S rRNA sequence methods, and the fastest growing strains with ideal fatty acid profiles for biodiesel production included Scenedesmus and Desmodesmus species (Growth Rate $\left(d^{-1}\right)>1$ ). All isolates in a small, but diverse taxonomic group of teststrains were tolerant of copper at wastewater-relevant concentrations. Overall, more than half of the isolated strains, particularly those from stormwater ponds, show promise as candidates for biofuel feedstock. 


\title{
Screening microalgae isolated from urban storm- and wastewater systems
} as feedstock for biofuel

\author{
Submitted by: \\ Rebecca Massimi and Andrea E. Kirkwood ${ }^{1}$ \\ Faculty of Science \\ University of Ontario Institute of Technology \\ 2000 Simcoe Street North \\ Oshawa, Ontario \\ Canada \\ L1H $7 \mathrm{~K} 4$
}

${ }^{1}$ Corresponding Author:

e-mail: andrea.kirkwood@uoit.ca

tel: 905.721 .8668

fax: 905.721 .3304 


\section{Abstract}

2 Exploiting microalgae as feedstock for biofuel production is a growing field of research

3 and application, but there remain challenges related to industrial viability and economic

4 sustainability. A solution to the water requirements of industrial-scale production is the use of

5 wastewater as a growth medium. Considering the variable quality and contaminant loads of

6 wastewater, algal feedstock would need to have broad tolerance and resilience to fluctuating

7 wastewater conditions during growth. As a first step in targeting strains for growth in

8 wastewater, our study isolated microalgae from wastewater habitats, including urban stormwater-

9 ponds and a municipal wastewater-treatment system, to assess growth, fatty acids and metal

10 tolerance under standardized conditions. Stormwater ponds in particular have widely fluctuating

11 conditions and metal loads, so microalgae from this type of environment may have desirable

12 traits for growth in wastewater. Forty-three algal strains were isolated in total, including several

13 strains from natural habitats. All strains, with the exception of one cyanobacterial strain, are

14 members of the Chlorophyta, including several taxa commonly targeted for biofuel production.

15 Isolates were identified using taxonomic and 18S rRNA sequence methods, and the fastest

16 growing strains with ideal fatty acid profiles for biodiesel production included Scenedesmus and

17 Desmodesmus species (growth rate $\left(\mathrm{d}^{-1}\right)>1$ ). All isolates in a small, but diverse taxonomic

18 group of test-strains were tolerant of copper at wastewater-relevant concentrations. Overall, more

19 than half of the isolated strains, particularly those from stormwater ponds, show promise as

20 candidates for biofuel feedstock. 


\section{Introduction}

As the earth's human population increases, world energy demands and reliance upon

25 fossil fuels has continued to rise. Consequently, global carbon emissions, including green-house

26 gases, have increased and contributed to global climate warming. The need to move to fossil-fuel

27 alternatives is not only necessary for addressing anthropogenic climate change, but also

28 depleting world energy-stores (Hook et al. 2013). Algal biofuels in particular have been

29 identified as an exceptional source of carbon neutral, renewable energy (Sharif Hossain et al.

30 2008, Schenk et al. 2008, Clarens 2010). Their high photosynthetic efficiency, biomass

31 production, and ability to accumulate relatively large amounts of triacylglycerides (TAG) for

32 conversion to fatty acid methyl esters (FAME) have made them a desirable alternative to land-

33 plant biofuel crops. Unlike first and many second-generation biofuel feedstocks, microalgae can

34 be cultivated using saline, brackish or wastewater streams on non-arable land. Additionally, algal

35 feedstock can be harvested batch-wise throughout the year from industrial-scale

36 photobioreactors, reducing land, nutrient, and fresh water requirements (Guischina et al. 2006,

37 Graef et al. 2009). The success and economic viability of an microalgae-based biofuel industry

38 will depend on several factors, including the selection of robust strains that exhibit exceptional

39 growth rates, suitable biofuel lipid profiles, resistance to disease and predation, and tolerance to a

40 wide range of environmental parameters (Griffiths and Harrison 2009). Tolerance to

41 environmental conditions is an important, but often over looked characteristic when

42 bioprospecting for biofuels, and offers several benefits such as ease of cultivation and resiliency.

Griffiths and Harrison (2009) outlined a framework in the selection of appropriate algal

44 strains. It identified the selection of fast-growing strains optimized for local climatic conditions

45 as a fundamentally important quality. They also argued that lipid content as a key characteristic 
46 may not be as critical as previously thought, because fast growth encourages high biomass

47 productivity, and high biomass density can increase yield-per-harvest volume. Research to

48 increase growth rates and lipid production has identified optimal temperatures, $\mathrm{pH}$, photoperiods

49 and nutrients for several species (Lv et al. 2010, Sforza et al. 2012, Adams et al. 2013). These

50 parameters, however, are dissimilar among strains and require individual optimization.

51 Moving forward, it is recognized that bioprospecting for biofuel microalgae will require

52 assessments of individual and mixed-cultures of strains (Zhou et al. 2011). Additionally, ideal

53 candidate strains may need an inherent tolerance to sub-optimal growth conditions, since

54 wastewater from a variety of sources may be the most economically and environmentally

55 feasible growth medium. As a first step in assessing temperate-climate microalgae for their

56 potential as biofuel feedstock, we aimed to isolate and culture strains from several engineered

57 wastewater systems that included urban stormwater ponds and a municipal wastewater system.

58 These environments were targeted because they are known to support algal communities, but

59 also experience fluctuating conditions that include variation in contaminant loads and residence-

60 time.

61 For example, we know that stormwater ponds typically have elevated metal

62 concentrations (Campbell 1994; Marsalek and Marsalek 1997; Karlsson et al. 2010), including

63 the ponds in our study (Vincent and Kirkwood 2014). It also has been well documented that

64 municipal wastewaters have elevated levels of metals and other contaminants (Chambers et al.

65 1997; Gagnon and Saulnier 2003; Wang et al. 2005; Principi et al. 2006). Hence, these

66 engineered environments were considered promising source habitats for microalgae with

67 inherent tolerance to fluctuating conditions and contaminant loads, including metals. Overall, the

68 primary goal of this study was to elucidate if certain algal taxa from these wastewater source- 
69 locations possessed growth, fatty acid, and metal-tolerance traits suitable for biofuel-feedstock 70 production.

71

72 Materials and Methods

73 Sample Collection and Strain Isolation

74 Three 1-L water samples were collected from nine urban stormwater ponds and two 75 natural reference ponds across Durham Region, Ontario, Canada between June and August, 76 2011. All of these ponds have been previously described using a similar numbering scheme in 77 Vincent and Kirkwood (2014). In June, 2011, 3-L of municipal wastewater was collected from 78 each of three locations along the secondary treatment system of the Corbett Creek activated 79 sludge Water Pollution Control Plant in Whitby, Ontario, Canada. Additionally, several litres of water were collected from Lake Ontario at a single nearshore location in Whitby, Ontario to expand the isolations from natural, local habitats. Sub-samples of all collected water were transferred to sterile 250-mL Erlenmyer flasks stoppered with cotton bunts on a light bank table (12:12 dark/light cycle) in triplicate. Upon confirmation of algal growth by visual inspection, $10-\mathrm{mL}$ sample aliquots were transferred to 250-mL Erlenmyer flasks and enriched with 90-mL of two defined media recipes: BG11 (Rippka et al. 1979) modified by reducing $\mathrm{NaNO}_{3}$ by one-tenth stock concentration; and CHU10 (Stein et al. 1973). Two media types were employed to broaden isolation success for a diversity of strains, and both had nitrogen and phosphorus concentrations on par with ranges typically found in the municipal-wastewater system of our study (unpublished data) and stormwater ponds (Vincent and Kirkwood 2014). F2 vitamin mixture (Guillard 1973) was added by syringe filter (Progene)

91 to both media types after autoclaving. Isolation of unialgal strains was accomplished by methods 
92 outlined by Andersen and Kawachi (2005). In brief, mixed-culture samples were serially diluted,

931 in 10 with sterile millipore water and spread plated on to $1.5 \%$ agar plates. Visible and distinct

94 colonies were pegged with sterile loop and re-cultured in BG11 or CHU 10 media and examined

95 microscopically to verify they were a single strain throughout the study period,with re-culturing

96 every three weeks. Isolated strains were observed using an EVOS xl core inverted microscope at

$97400 \mathrm{X}$ to ensure unialgal status, and subsequent sequencing of strains confirmed this. Tentative

98 taxonomic strain identification was assigned based upon morphological descriptions in Sheath

99 and Wehr (2003).

100

101 Growth Assays

102 Growth assays were conducted under standardized conditions to determine growth rate 103 and generation time for all isolates. A 10-mL inoculum of exponentially-growing stock-culture 104 was aseptically introduced to $90-\mathrm{mL}$ of sterile isolation media and grown in cotton-stoppered 105 flasks on a cool-white fluorescent plate-glass light table $\left(20-22^{\circ} \mathrm{C}, 12: 12\right.$ dark/light cycle $)$ and 106 shaken by hand once a day. Algal cell concentration was determined by microscopic

107 enumeration using a Brightline haemocytometer on a VistaVision compound light microscope at 108 100X magnification. The optical density of 1-mL samples was measured at 550nm every 24-hrs 109 for a seven-day period using the Genesys 10S UV/VIS Spectrometer. These data were used to 110 construct growth curves for each algal strain. Specific growth rate $(\mu)$, and generation time $\left(T_{h}\right)$ 111 were calculated as per Guillard (1973) over a period of exponential growth.

112

113 Antibiotic Treatment of Algal Isolates 
114 Great care was taken to attain axenic cultures to remove the influence of bacteria on

115 FAME profiles (Stemmler et al. 2016) using a modified antibiotic treatment method adapted

116 from Jones et al. (1973). Isolated strains were first treated with a serial dilution of antibiotics (a

117 combination of Penicillin G sodium salt and Streptomycin sulfate) (Bioshop Canada) for an

118 exposure period of 24 hours. Algal colonies were selected from the lowest antibiotic

119 concentration that had no bacterial growth. Aliquots of the exposed strains were transferred to

120 fresh media, with no antibiotics, after 24 hours, followed by pour plate preparation, $1 \%$ peptone

121 and $1.5 \%$ agar, to evaluate bacterial contamination in addition to microscopic observation.

122 Strains deemed to be axenic were monitored by this method once a month to ensure axenic status

123 was sustained. Strains that were found to be non-axenic were re-treated, but a few non-axenic

124 strains were classified as such if bacterial contamination could not be removed. Only axenic

125 strains were assessed for fatty acid analyses.

126

127

DNA Extraction, Amplification, and Sequencing

128

Genomic DNA of isolated strains was extracted using the commercial kit UltraClean

129 Plant DNA Isolation kit (MoBIO, USA). Cell lysis was achieved by chemical, SDS and

130 mechanical means using a Vortex Genie with horizontal microtube attachment (Scientific

131 Industries, USA). Bead tubes provided by the extraction kit were subjected to three, 5-minute

132 bead beating sessions at $3200 \mathrm{rpm}$. Samples rested in the tubes on ice for 5 minutes between

133 bead beating sessions. Upon completion of cell disruption, $20 \mu \mathrm{L}$ of RNase A (Geno

134 Technology, USA) was added and vortexed gently for 10 minutes. Extracted DNA was

135 quantified at 260/280nm by UV-Spectrophotometry (Gensys $10 \mathrm{~S}$ UV/VIS) and frozen at $-20^{\circ} \mathrm{C}$

136 or kept at $4^{\circ} \mathrm{C}$ until PCR amplification. 
138 et al. 1990) were used to prime PCR at a concentration of $1.0 \mu \mathrm{mol}$. Reactions were carried out 139 using Illustra Ready-To-Go PCR beads (GE Healthcare, USA) in a final volume of $25 \mu \mathrm{L}$. The

140 PCR reaction was performed using the T100 Thermal cycler (BIORAD, Canada) with the

141 following cycle parameters: initial denaturation $96^{\circ} \mathrm{C}$ for $3 \mathrm{~min}$, annealing at $51^{\circ} \mathrm{C} / 1 \mathrm{~min}$, and 142 extension at $72^{\circ} \mathrm{C}$ for $1.30 \mathrm{~min}$. This was followed by 29 cycles of denaturation at $93^{\circ} \mathrm{C} / 1.30$

$143 \mathrm{~min}$, annealing at $51^{\circ} \mathrm{C}$ for 1.30 and extension at $72^{\circ} \mathrm{C}$ for $1.30 \mathrm{~min}$, followed by a final

144 extension step at $72^{\circ} \mathrm{C}$ for $5 \mathrm{~min}$. Strains that would not amplify by this method were amplified 145 using the forward NS1 primer and reverse 18L primer (Hamby and Zimmer 1991), along with a 146 touchdown PCR cycle with annealing beginning at $61^{\circ} \mathrm{C}$ and reducing by $2^{\circ} \mathrm{C}$ every 2 cycles 147 until $51^{\circ} \mathrm{C}$ was reached. Gel purification of PCR bands was carried out using the Wizard SV Gel 148 and PCR Clean-Up System (Promega, USA). Modifications were made to the general protocol 149 with the addition of an extra rinse of the column with membrane wash-solution as well as an 150 additional 1-minute spin at $16000 \mathrm{x} \mathrm{g}$ with the lid off to aid in evaporation of wash solution. 151 Extracted bands were sent to the Génome Québec Innovation Centre, McGill University, Canada 152 for Sanger sequencing.

153 Sequencing results were locally aligned using the NCBI Nucleotide BLAST and closest 154 matches assigned based on sequences from the NCBI database. BLAST matches that aligned 155 closely, between 90-99\% with culture strains, were selected and added to sequence comparisons 156 in addition to more distantly related species within each family. Only NS1 region sequences 157 greater than 400 base pairs (bp) were included in further phylogenetic analyses. These sequences 158 were deposited into the NCBI database and accession numbers for each sequence were acquired. 

et al. 2008; Dereeper et al. 2010), which comprised a series of steps in the analysis. Sequences

161 were aligned and configured with the highest accuracy using MUSCLE (v 3.8.31) (Edgar 2004).

162 After alignment, ambiguous regions containing gaps or poorly aligned regions were removed 163 with Gblocks (v0.91b) using the following parameters: minimum length of a block after gap

164 cleaning=10; no gap positions were allowed; all segments with contiguous non-conserved 165 positions bigger than 8 were rejected; and minimum number of sequences for flank position was $16685 \%$ (Castresana 2000). The phylogenetic tree was reconstructed using the neighbour-joining 167 method (Saitou and Nei 1987, Gascuel 1997) implemented in the BioNJ program with 1000 168 bootstrap replicates (Felsenstein 1985; Elias and Lagergren 2007). The analysis involved 45 169 nucleotide sequences with an average sequence length of $735 \mathrm{bp}$. Graphical representation and 170 editing of the phylogenetic tree was performed with TreeDyn (v198.3) (Chevenet et al. 2006).

Fatty Acid Methyl Esters (FAME) Analysis To avoid possible confounding effects of bacteria, only axenic isolates (thirty-four in total) were subjected to fatty acid analysis. Isolated strains were grown to stationary phase under 175 previously described growth conditions and 10-mL subsamples were transferred to 14-mL glass 176 tubes with lids and centrifuged at $16000 \mathrm{rpm}$ (Sorval ST16, Thermo Scientific, USA) for five 177 minutes. Pelleted biomass was frozen at $-20^{\circ} \mathrm{C}$ for 48 hours followed by $24-48 \mathrm{hrs}$ of 178 lyopholization with a modulyoD freeze dryer (Thermo Scientific, USA). A direct method of 179 transesterfication of algal fatty acids was performed as per O’fallon et al. (2007). A 100 ppm 180 nonadecanoic acid methyl ester C19:0 (Sigma Aldrich, Canada) internal standard was added to 181 each sample followed by analysis by Gas Chromatography/Mass Spectrometry (GC/MS). 

with HP-5ms Ultra Inert GC Column, $30 \mathrm{~m}$ x $0.25 \mathrm{~mm}$ x $0.25 \mu \mathrm{m}$, (Agilent J\&W). A split ratio of 10:1 was used for $3.5 \mathrm{~min}$ with a flow rate of $1.0 \mathrm{~mL} / \mathrm{min}$, helium carrier gas. The oven temperature was held at $135^{\circ} \mathrm{C}$ for 4 minutes and increased by $4{ }^{\circ} \mathrm{C} / \mathrm{min}$ until $250{ }^{\circ} \mathrm{C}$, where it was held for 10 minutes until run-end. A Varian 240 Ion Trap Mass Spectrometer detector was used and fame peaks were identified based upon spectral comparison and retention times to FAME standards: BAME and Supleco C8:0-C24:0 (Sigma Aldrich, Canada). A negative control was included in the FAME process as a quality measure and analyzed under identical sample conditions to ensure peaks obtained were attributable to microalgae samples. Ramos et al. (2009) and Nascimento et al. (2013). ASTM Standard D675 for biodiesel quality requires a minimum Cetane Number $(\mathrm{CN})$ of 47 and a maximum Iodine Value (IV) of 120.

\section{Copper Toxicity Bioassays}

Five isolates representing diverse taxonomic genera were further characterized to assess their inherent tolerance to copper, a particularly toxic metal to microalgae and a metal that is commonly found in industrial and municipal wastewaters. Genera selected include:

Phycological Culture Collection strain Chlorella kesslerii CPCC266 was also tested as it is a commonly used bioassay reference-strain. A standard 72-hour static growth response bioassay was used to assess inherent tolerance to copper. The assay methodology was based on the protocol established by Environment Canada (2007). Prior to commencing the bioassays, all 
205 glassware, tips, and applicable materials were acid-washed in a 10\% HCL solution for a period 206 of 24 hours followed by triplicate rinse with Milli-Q ${ }^{\mathrm{TM}}$ filtered water. A stock Copper (II) Sulfate 207 Pentahydrate $\left(32 \mathrm{mg} \mathrm{L}^{-1} \mathrm{Cu}\right)$ solution was prepared with a solution of CHU 10 media and 208 sterilized by autoclave. The stock solution was used to aseptically prepare copper concentrations 209 of $0.01,0.1,0.32,1.0$ and 3.2 parts per million $(\mathrm{ppm}) \mathrm{Cu}$, diluted with sterile CHU 10 media. All 210 concentrations and control cultures were prepared in triplicate to a final volume of $25-\mathrm{mL}$ in 50 $211 \mathrm{~mL}$ Erlenmyer flasks. Innocula (1-mL) from exponential phase cultures were added to three 212 replicate flasks with each test concentration and maintained under the same growth conditions in 213 a controlled environment incubater with shaker table (Algaetron AG130-ECO) at $22^{\circ} \mathrm{C}+/-2^{\circ} \mathrm{C}$ 214 under $12 \mathrm{~h}$ light/dark cycles at $150 \mathrm{mmol}$ photons $\mathrm{m}^{-2} \mathrm{~s}^{-1}$ and $200 \mathrm{rpm}$. The $\mathrm{pH}$ of each replicate 215 was monitored daily using an Oakton pH/Ion 510 bench meter. Fluorescence measurements of 216 chlorophyll $a$ were taken at 24-hr intervals using an Aquafluor Hand Held fluorometer, whereby 217 the chlorophyll $a$ solid secondary standard (Turner Designs, USA) was used as a qualitative 218 calibration tool for chlorophyll $a$ measurement. The growth rate was calculated as previously 219 described and data were normalized to percent-control. Growth-rate data were also used to 220 calculate percent inhibition:

$$
\% \mathrm{I}=\frac{\mathrm{C}-\mathrm{X}}{\mathrm{C}} \times 100
$$

222 Where $\mathrm{C}=$ average control growth-rate, $\mathrm{X}=$ average test-concentration growth-rate.

\section{Results}

In total, forty-three algal strains were isolated from all habitat types. Tentative taxonomic assignments were given to all isolates and, with the exception of one cyanobacterial strain

227 (Microcystis sp. Sp21.01), NCBI BLAST searches of partial 18S rRNA sequences were 
228 performed (Table 1). All eukaryotic isolates are members of the algal division Chlorophyta,

229 which is a diverse group of green microalgae. Taxonomic assignment and BLAST matches were

230 fairly congruent, but there were several exceptions. All isolates were initially characterized for

231 growth-rate under standardized conditions (Table 1), and for all strains, exponential growth was

232 most commonly observed to last up to three days. Fastest growing strains came from stormwater

233 ponds and included Scenedesmus sp Sp19.011 and Desmodesmus sp. Sp19.15, which doubled

234 their biomass in just over 13 hours. In contrast, the slowest growing strains Scenedesmus sp.

235 Sp21.12 and Chlorella sp. Sp21.20 had generation times between $40-42$ hours. Over $60 \%$ of the

236 strains were found to have a generation time less than 24 hours (Table 1).

237 A subset of twenty-seven isolates with NS1 sequences greater than $400 \mathrm{bp}$ were used with

238 eighteen NCBI database-taxa to reconstruct an unrooted neighbour-joining phylogenetic tree

239 (Fig. 1). All strains included in the tree belong to the Chlorophyceae and Trebouxiophyceae

240 classes. Tree topology distinctly groups isolates into families and genera. In total, the tree

241 demarcates study-isolates into seventeen unique phylotypes based on branch lengths $\leq 0.001$

242 base-pair substitutions per site. Most isolates had sequence matches with taxa from the BLAST

243 database, with the exception of only a few including: Monoraphidium sp. Sp19.015,

244 Scenedesmus sp. Sp19.011, Desmodesmus sp. Sp19.15 and Chlamydomonas sp. SpU9.

245 FAME results for thirty-four axenic isolates identified seven different fatty acids,

246 including saturated (lauric acid (C12:0) and palmitic acid (C16:0)), monounsaturated (oleic acid

247 (C18:1)) and polyunsaturated (linoleic acid (C18:2), hexadecatetraenoate (C16:4(n-3) and

248 eicsoatetraenoic acid (C20:4)) forms. Palmitic and oleic fatty acids were the predominant lipid

249 components found in all strains. Several strains including Chlamydomonas sp. SpU9,

250 Chlamydomonas sp. Sp19.40, Ankistrodesmus sp. LO47 and Chlorella sp. LO51 had a large 
251 percentage (70-90\%) of their total FAME lipid as palmitic acid. Desmodesmus sp. WW39 and

252 Scenedesmus sp. Sp16.34 had oleic acid greater than $80 \%$ of their total FAME lipid profile.

253 Chlorococcum sp. Sp17.022 was the only strain observed to have oleic acid C18:1 present in

254 both cis- and trans- forms. One of the most unique profiles belongs to Chlorella sp. Sp21.02,

255 which was found to have 53\% of its lipids in polyunsaturated forms (Fig. 2). There was no

256 apparent distinction of FAME profiles among strains isolated from different source-locations

257 (see supplemental information).

258 To determine if there was any congruence among strains with respect to lipid

259 composition and phylogenetic relatedness, the FAME profiles of strains sharing a phylotype with

260 at least one other strain were compared using hierarchical cluster analysis (Fig. 3). The Bray-

261 Curtis similarity dendrogram grouped strains of the same phylotype as being most similar based

262 on their FAME profile. The cophenetic correlation coefficient of 0.87 indicates that the

263 dendrogram adequately preserved the pairwise distances among strains. Bootstrap scores were

264 mixed, but were moderate to strong for most nodes in the dendrogram. Strains Scenedesmus $s p$.

265 Sp12.36 and Scenedesmus sp. LO48 are the same phylotype and had the most similar FAME

266 profiles (>95\% similarity). In contrast, Ankistrodesmus sp. LO47 and Ankistrodesmus sp. Sp1.50,

267 which are the same phylotype, were only about 55\% similar based on their FAME profiles. Even

268 so, they were grouped as most similar among isolates in the cluster dendrogram (Fig. 3).

269 With respect to biodiesel quality, twenty-eight isolates had a CN greater than 47, and

270 thirty isolates did not exceed an IV of 120 (Table 2). In combination, twenty-eight isolates had

271 acceptable CN and IV values according to the ASTM standard. The degree of unsaturation

272 among isolates was quite varied, ranging from very low (10.6) for Chlorella $s p$. Sp23.13 to very

273 high (120) for Ankistrodesmus sp. Sp1.50. Long-chain saturation factor also varied among 
274 isolates, where isolate Scenedesmus sp. Sp16.34 had the lowest value (0.55) by an order of

275 magnitude, and Chlorella sp. Sp23.13 had the highest value (8.94). The Saponification Value

276 was less varied among strains, where most had values varying from 200-210. Strain

277 Chlamydomonas sp. SpU9 had a notably high SV of 241. The majority of isolates had negative-

278 integer values for Cold Filter Plugging Point. Scenedesmus sp. Sp16.34 in particular, had a CFPP

279 as low as $-15^{\circ} \mathrm{C}$. In contrast, Sp23.13 had a relatively high CFPP at $12^{\circ} \mathrm{C}$.

280

To assess the inherent tolerance of algal isolates to the common wastewater contaminant

281

copper, five representative-strains from a variety of taxonomic groups were subjected to static

282

growth-response bioassays. The cyanobacterial strain Microcystis sp. Sp21.01 was the least

283 tolerant to copper, having complete growth inhibition at $0.32 \mathrm{mg} \cdot \mathrm{L}^{-1}$ or higher. The two

284 stormwater pond isolates Monoraphidium sp. Sp17.38 and Selenastrum sp. Sp14.35 had

285 significantly higher (Student's t-test $\mathrm{p}<0.05$ ) tolerance to $0.32 \mathrm{mg} \cdot \mathrm{L}^{-1}$ copper than the reference

286 strain Chlorella kesslerii CPCC26. The most tolerant strain was Selenastrum sp. Sp14.35, which

287 had the highest growth rate at $1 \mathrm{mg} \cdot \mathrm{L}^{-1}$ copper. No strains could grow at the highest test

288 concentration $3.2 \mathrm{mg} \cdot \mathrm{L}^{-1}$. At municipal-wastewater relevant concentrations of copper, all test

289 strains, with the exception of Microcystis sp. Sp21.01, had minimal to no growth inhibition at the

290 highest copper concentration $0.1 \mathrm{mg} \cdot \mathrm{L}^{-1}$ (Table 3).

291

292 Discussion

293 Diversity of algal isolates

294 All isolated algal strains (with the exception of one cyanobacterial isolate) belong to the

295 Chlorophyta, a class of algae that includes taxa commonly used in algal biofuel research and 296 application (Mata et al. 2010). In particular, Chlorella sp. and Scenedesmus sp. are the most 
297 commonly used for biofuel feedstock, and our study isolated several strains from each of these

298 genera. Chlorophyte taxa such as the strains from our study are easy to culture, which in part, is

299 likely why they are common in biofuel studies. Yet, these taxa have also been shown to be

300 relatively good lipid producers (Mata et al. 2010), which increases their utility as feedstock in

301 biodiesel production. As such, all source locations in this study, and in particular stormwater

302 ponds and the municipal wastewater treatment plant, were fruitful habitats for isolation of lipid-

303 rich strains suitable for biodiesel production.

304

Several discrepancies between taxonomic assignment and BLAST match (Table 1) was

305 not entirely unexpected as this can be a common scenario. Though many chlorophyte species

306 exhibit type-features, such as spine and coenobium formation, culture condition will often affect

307 these characteristics used in identification. Morphological heterogeneity also makes algal

308 identification challenging, so it is possible that some strains were misidentified. In contrast, $18 \mathrm{~S}$

309 rRNA sequencing can be useful in distinguishing phylotypes of morphologically similar strains

310 (Friedl, 1995, Lewis and McCourt, 2004). This was evident in the phylogenetic tree

311 reconstruction, which provided a clear resolution to generic assignment for isolates in the tree. In

312 most instances, morphological similarities of clade members were supported by genetic

313 homology presented in the tree organization. BLAST sequence searches for some of the more

314 closely related Scenedesmus, Desmodesmus and Coleastrum taxa often returned similar local

315 alignment matches for query cover and percent identity, making them difficult to confirm solely

316 based on closest-match results. Again, the phylogenetic tree topology provided useful

317 clarification of misidentifications found in the BLAST database. Sequence databases are known

318 to have a small percentage ( 20\%) of their sequence collection to be mislabelled or misidentified

319 (Bridge et al, 2003, Vilgalys, 2003), and algal systematics is currently in flux. As such, definitive 
320 taxonomic and phylogenetic assignment for strains in this study will likely require further

321 classification in the future.

322 Algal growth and fatty acid production

323 Rapid growth rates are an important characteristic of biofuel feedstock, since fast-

324 growing strains would have increased yields in a shorter time-frame. According to Griffiths and

325 Harrison (2009), the average doubling time for green microalgae is $24 \mathrm{~h}$, which corresponds to a

326 growth-rate $(\mu)=0.69 \mathrm{~d}^{-1}$. Of the forty-three isolates evaluated, the majority of strains were able

327 to double their biomass in 24-hours or less (Table 1). Twelve isolates from our study could grow

$328 \geq 1.0 \mathrm{~d}^{-1}$ (Table 1), which is considered to be a relatively fast growth-rate for microalgae in

329 general, and thus a desirable trait for biofuel-feedstock. Many of the fastest growing taxa were

330 from stormwater ponds and included closely related genera such as Scenedesmus, Desmodesmus,

331 and Ankistrodesmus (Fig. 1). If these phylogenetically related taxa were to be targeted for

332 isolation from other systems, our results from a subset of strains would suggest that they may

333 have similar fatty acid profiles (Fig. 2), even for those of the same phylotype (Fig. 3). However,

334 calculations presented in Table 2 show phylogenetically similar strains (e.g., Sp12.07 and

335 Sp12.21) have differing biodiesel qualities. This finding concurs with the Culture Collection of

336 Algae at Goettingen University (SAG) study that found similarities among fatty acid distribution

337 patterns were only found at phyla and class levels (Lang et al. 2011). When accounting for all

338 strains that were assessed for their fatty acid profiles (Fig. 2, Table 2), it is apparent that the

339 diverse array of taxa, even from the same class, exhibited a broad range of variation in fatty acid

340 composition. The observed variation in growth rate and fatty acid profile among strains in our

341 collection supports the continued need to characterize microalgae at the strain-level, rather than

342 targeting a certain family or genera, when bioprospecting for biofuel candidates. 
344 (hexadecanoic) acid, stearic C18:0 (octadecanoic) acid, oleic C18:1 (9(Z)-octadecenoic) acid,

345 linoleic C18:2 (9(Z),12(Z)-octadecadienoic) acid, and linolenic C18:3 (9(Z),12(Z),15(Z)-

346 octadecatrienoic) acid (Knothe 2008). The dominant saturated fatty-acid in most strains from this

347 study was C16:0 palmitic acid, and in many cases, represented approximately 50\% of the total

348 fatty-acid profile. The dominant unsaturated fatty acid in most strains was C18:1 oleic acid, and

349 it too represented about $50 \%$ of the total fatty acid profile among several strains. Biofuels with

350 high oleic acid content have been reported to have reasonable ignition quality, combustion heat,

351 cold filter plugging point (CFPP), oxidative stability, viscosity, and lubricity (Chen 2012). Hu et

352 al. (2008) confirm that fatty acids with carbon chain lengths from 16 to 18 units are ideal

353 precursors for biodiesel production. Not only does carbon chain length provide a basis for

354 deriving biodiesel, but specifically, the saturation versus unsaturation garners characteristics that

355 make the fuel more versatile.

356 Potential for biodiesel production

357 Biodiesel derived from microalgae with more saturation provide a higher cetane number,

358 would have lower NOx emissions, and have shorter ignition delay time (Cherisilp and Torpee

359 2012). Nevertheless, this can come at a cost since lower temperatures would cause saturated

360 fatty- acids to solidify due to their high melting point (Doğan and Temur 2013). Unsaturated

361 fatty-acids require less heating and are often liquids at room temperature, however, the higher the

362 number of double-bonds, the more prone the fuel is to producing NOx emissions (Gopinath et al.

363 2010). Gopinath et al. (2010) claim that having a 50/50 blend of saturated and unsaturated fatty

364 acids produces better thermal efficiency and reduces NOx emissions. Based on this biodiesel

365 characteristic, many of the strains isolated in this study have desirable fatty-acid profiles 
366 reflecting a $\sim 50 / 50$ saturated/unsaturated blend.

367 TAG commonly accumulate in many algal species as a storage product. As culture

368 resources are depleted and algal growth slows, so does the production of new membrane

369 compounds such as phosphoglycerides, glycosylglycerides and sterols. Under these conditions,

370 fatty-acid production is diverted to TAG synthesis (Guschina and Harwood 2006). This

371 metabolic shift results in a trade-off impacting biomass production. Griffiths and Harrison (2009)

372 reported that cultivation conditions focusing on biomass productivity instead of lipid production

373 per cell may ultimately be more beneficial and more efficient in increasing total lipid

374 productivity. Several fast growing isolates from this study (including Scenedesmus sp. Sp1.41,

375 Scenedesmus sp. Sp19.011, and Desmodesmus sp. Sp19.15) have ideal biodiesel properties based

376 on their Cetane Number, Iodine Values and Degree of Unsaturation (Table 2). Hence, these

377 strains may represent the best candidates for optimal lipid yields based on growth-rate alone.

378 Algal copper tolerance

379 Although a select, but diverse group, of isolates were tested for copper tolerance, all

380 chlorophyte strains exhibited high tolerance at wastewater-relevant concentrations (Table 3).

381 Thus it is plausible that many chlorophyte isolates in our collection would likely have some

382 inherent tolerance to copper if one extrapolates from the copper bioassay results. Others have

383 also recognized the higher tolerance thresholds of chlorophyte microalgae to wastewater

384 conditions, focusing primarily on Chlorella and Scenedesmus strains (Lau et al. 1995; Bhatnagar

385 et al. 2010; Ruiz-Marin et al. 2010). Interestingly, the only non-chlorophyte strain in our study

386 (Microcystis) was uniquely less tolerant to copper than the chlorophyte strains, even though it

387 was also isolated from a stormwater pond. It is also interesting that two of the stormwater pond

388 isolates Monoraphidium sp. Sp17.38 and Selenastrum sp. Sp14.35 were notably tolerant to 
389 copper at concentrations orders of magnitude higher than their source stormwater ponds (Table

390 3). Therefore, these strains in particular may be ideal candidates for industrial-wastewater

391 feedstock since they are relatively fast growers (Table 1), have ideal fatty-acid profiles (Fig. 2

392 and Table 2), and have inherent tolerance to the algicidal-metal copper (Table 3).

393 Conclusions

394 Bioprospecting of algal strains for use in biofuel production is a relatively new trend.

395 Though our study is the first to target biofuel bioprospecting efforts in stormwater ponds and a

396 municipal wastewater system, the dominant taxa isolated, including Chlorella, Scenedesmus, and

397 Desmodesmus, are cosmopolitan in freshwater environments. Strains identified as the species

398 Scenedesmus obliquuss and Chlorella leuteoiviridis in blast matches were prevalent in both

399 stormwater ponds and the wastewater treatment facility, and they typically out-competed other

400 species during cultivation. Zhou et al. (2011) found similar results in isolations of microalgae

401 from wastewater sites in the United States, isolating several species of Chlorella. Past efforts to

402 isolate microalgae from various habitats including wastewater systems was mainly for

403 wastewater remediation. Chlorella and Scenedesmus are common taxa isolated for this purpose,

404 especially for nutrient removal (Tam and Wong 1989; Tam and Wong; 1990, Gonzalez et al.

405 1997; Woertz et al. 2009; Chinnasamy et al. 2010). Nutrient removal by microalgae cultivated in

406 wastewater would provide a value-added benefit during biofuel-feedstock production.

407 While the results presented here are only a first step in assessing algal strains from

408 wastewater habitats as biofuel-feedstock candidates, the ultimate goal is to establish and select

409 strains most tolerant to municipal and/or industrial wastewater conditions. The use of wastewater

410 to support algal biomass production is not a new approach, but it is for biofuel feedstock

411 production. Several studies have all concluded that there is great potential for algal biofuel 
412 production using wastewater (Pittman et al. 2011; Bhatnagar et al. 2011; Christenson and Sims

413 2011). Yang et al. (2011) looked at the total water and nutrient requirements of microalgae-based

414 biofuels and found that biofuels sourced from wastewater decreased total water requirements by

$41590 \%$ in comparison to freshwater sourcing without recycling. What has not been investigated

416 explicitly is the viability of using wastewater on a continuous basis in a pond or photobioreactor

417 system growing single or mixed strains of microalgae. Broad variations can occur in wastewater

418 quality, in addition to fluctuations in toxic-metal constituents (Cole et al. 1989; Ahuwalia et al.

419 2007). In the case of municipal wastewater, the nutrient and contaminant content can vary daily

420 depending on the source-population. As such, future studies of biofuel microalgae, including

421 promising isolates from this study, would need to be assessed for their tolerance and resilience to

422 fluctuating wastewater conditions while maintaining an acceptable growth rate and lipid yield. 


\section{References}

424 Ahluwalia SS, Goyal D (2007) Microbial and plant derived biomass for removal of heavy metals

425 from wastewater. Bioresource Technol 98:2243-2257

426 Adams C, Godfrey V, Wahlen B, Seefeldt L, Bugbee B (2013) Understanding precision nitrogen

427 stress to optimize the growth and lipid content tradeoff in oleaginous green microalgae.

428 Bioresource Technol 131:188-194

429 Andersen RA, Kawachi.M (2005) Traditional microalgae isolation techniques. In: Andersen RA

430 (ed) Algal culturing techniques. Elsevier, Amsterdam, pp 83-100

431 Bhatnagar A, Bhatnagar M, Chinnasamy S, Das K (2010) Chlorella minutissima - a promising

432 fuel alga for cultivation in municipal wastewaters. Appl Biochem Biotechnol 161:23-536

433 Bhatnagar A, Chinnasamy S, Singh M, Das KC (2011) Renewable biomass production by

434 mixotrophic algae in the presence of various carbon sources and wastewaters. Appl Energ

$435 \quad 88: 3425-3431$

436 Bridge PD, Spooner BM, Roberts PJ, Panchal G (2003) On the unreliability of published DNA

437 sequences. New Phytol 160:43-48

438 Campbell KR (1994) Concentrations of heavy metals associated with urban runoff in fish living

439 in stormwater treatment ponds. Arch Environ Con Tox 27:352-356

440 Castresana J (2000) Selection of conserved blocks from multiple alignments for their use in

441 phylogenetic analysis. Mol Biol Evol 17:540-52

442 Chambers PA, Allard M, Walker SL, Marsalek J, Lawrence J, Servos M, Busnarda J, Munger

443 KS, Adare KA (1997) Impacts of municipal wastewater effluents on Canadian waters: a

444 review. Water Qual Res J Can 32:659-713

445 Chen M, Liu T, Chen X, Chen L, Zhang W, Wang J, Gao L, Chen Y, Peng X (2012) Subcritical 
446 co-solvents extraction of lipid from wet microalgae pastes of Nannochloropsis sp. Eur J

$447 \quad$ Lipid Sci Technol 114:205-212

448 Cherisilp B, Torpee S (2012) Enhanced growth and lipid production of microalgae under

449 mixotrophic culture condition: Effect of light intensity, glucose concentration and fed-batch

$450 \quad$ cultivation. Bioresource Technol 110:510-516

451 Chevenet F, Brun C, Banuls AL, Jacq B, Chisten R (2006) TreeDyn: towards dynamic graphics

452 and annotations for analyses of trees. BMC Bioinform doi: 10.1186/1471-2105-7-439

453 Chinnasamy S, Bhatnagar A, Hunt RW, Das KC (2010) Microalgae cultivation in a wastewater

454 dominated by carpet mill effluents for biofuel applications Bioresource Technol 101:3097-

$455 \quad 3105$

456 Christenson L, Sims R (2011) Production and harvesting of microalgae for wastewater treatment,

457 biofuels, and bioproducts. Biotechnol Adv 29:686-702

458 Clarens AF, Resurreccion EP, White MA, Colosi LM (2010) Environmental life cycle

459 comparison of algae to other bioenergy feedstocks. Environ Sci Technol 44:1813-1819

460 Coale KH, Flegal AR (1989) Copper, zinc, cadmium and lead in surface waters of lakes Erie and

$461 \quad$ Ontario. Sci Tot Environ 87:297-304

462 Dereeper A, Audic S, Claverie JM, Blanc G. (2010) BLAST-EXPLORER helps you building

463 datasets for phylogenetic analysis. BMC Evol Biol doi: 10.1186/1471-2148-10-8

464 Dereeper A, Guignon V, Blanc G, Audic S, Buffet S, Chevenet F, Dufayard JF, Guindon S,

465 Lefort V, Lescot M, Claverie JM, Gascuel O (2008) Phylogeny.fr: robust phylogenetic

466 analysis for the non-specialist. Nucleic Acids Res. 36(suppl 2);W465-W469

467 Doğan, TH, Temur H (2013) Effect of fractional winterization of beef tallow biodiesel on the

468 cold flow properties and viscosity. Fuel 108:793-796 
469 Edgar RC (2004) MUSCLE: multiple sequence alignment with high accuracy and high

$470 \quad$ throughput. Nucleic Acids Res. 32:1792-7.

471 Elias I, Lagergren J (2007) Fast computation of distance estimators. BMC Bioinform doi:

$472 \quad 10.1186 / 1471-2105-8-89$

473 Environment Canada (2001) The state of municipal wastewater effluents in Canada (State of the

474 Environment report). Indicators and Assessment Office, Environment Canada. Minister of

475 Public Works and Government Services Canada, Ottawa, Ontario, Cat. No. En1-11/96E

476 Environment Canada (2007) Biological test method: Growth inhibition test using a freshwater

477 alga EPS 1/RM/25 (Second Edition), Environmental Science and Technology Centre Science

478 and Technology Branch, Ottawa, Ontario, Canada.

479 Felsenstein J (1985) Confidence limits on phylogenies: An approach using the bootstrap.

$480 \quad$ Evolution 39:783-791

481 Friedl T (1995) Inferring taxonomic positions and testing genus level assignments in coccoid 482 green lichen algae: a phylogenetic analysis of 18S Ribosomal RNA sequences from 483 Dictyochloropsis reticulata and from members of the genus Myrmecia (CHLOROPHYTA, $484 \quad$ TREBOUXIOPHYCEAE CL. NOV.) J Phycol 4:632-639.

485 Gagnon C, Saulnier I (2003) Distribution and fate of metals in the dispersion plume of a major 486 municipal effluent. Environ Pollut 124:47-55

487 Gascuel O (1997) BIONJ: an improved version of the NJ algorithm based on a simple model of 488 sequence data. Mol Biol. Evol. 14:685-95

489 Gonzalez LE, Canizares RO, Baena S (1997) Efficiency of ammonia and phosphorus removal 490 from a Colombian agroindustrial wastewater by the microalgae Chlorella vulgaris and 491 Scenedesmus dimorphus. Bioresour. Technol 60:259-262 
492 Gopinath A, Puhan S, Nagarajan G (2010) Effect of unsaturated fatty acid esters of biodiesel

493 fuels on combustion, performance and emission characteristics of a DI diesel engine. Int J

$494 \quad$ Energ Environ 1:411-430

495 Graef G, LaVallee BJ, Tenopir P, Tat M, Schweiger B, Kinney AJ, Van Gerpen JH, Clemente 496 TE (2009) A high-oleic-acid and low-palmitic-acid soybean: agronomic performance and 497 evaluation as a feedstock for biodiesel. Plant Biotechnol J 7:411-421

498 Griffiths MJ, Harrison ST (2009) Lipid productivity as a key characteristic for choosing algal 499 species for biodiesel production. J Appl Phycol 21:493-507

500 Guillard RR (1973) Methods for microflagellates and nannoplankton. In: Stein JR, Hellebust JA,

501 Craigie JS (eds) Handbook of phycological methods: culture methods and growth

502 measurements. Cambridge University Press, Cambridge, pp.69-85

503 Guischina A, Harwood JL (2006) Algal lipids and their metabolism. Prog Lipid Res 45:160-168

504 Hamby RK, Zimmer EA (1991) Ribosomal RNA as a phylogenetic tool in plant systematics. In:

505 Soltis P, Soltis D, Doyle J (eds) Molecular systematics in plants. Routledge, Chapman and

$506 \quad$ Hall, New York, pp. 50-91

507 Hook M, Tang Xu (2013) Depletion of fossil fuels and anthropogenic climate change - A

508 review. J En Pol 52:797-809

509 Hu Q, Sommerfeld M, Jarvis E, Ghirardi M, Posewitz M, Seibert M, Darzins A (2008)

510 Microalgal TAGs as feedstocks for biofuel production: perspectives and advances. Plant J

$511 \quad 54: 621-639$

512 Jones AK, Rhodes ME, Evans SC (1973) The use of antibiotics to obtain axenic cultures of

$513 \quad$ algae. Br Phycol J 8:185-196

514 Karlsson K, Viklander M, Scholes L, Revitt M (2010) Heavy metal concentrations and toxicity 
515 in water and sediment from stormwater ponds and sedimentation tanks. J Hazard Mater

$516 \quad 178: 612-8$

517 Knothe G (2008) “Designer” biodiesel: Optimizing fatty ester composition to improve fuel 518 properties. Energ Fuels 22:1358-1364

519 Lang I, Hodac L, Friedl T, Feussner I (2011) Fatty acid profiles and their distribution patterns in 520 microalgae: a comprehensive analysis of more than 2000 strains from the SAG culture 521 collection. BMC Plant Biol doi: 10.1186/1471-2229-11-124

522 Lau PS, Tam NFY, Wong YS (1995) Effect of algal density on nutrient removal from primary

523 settled wastewater Environ Pollut 89:59-66

524 Lewis LA and McCourt RM (2004) Green algae and the origin of land plants. Am. J Botany $52591: 1535-1556$.

526 Lv JM, Cheng L, Xu X, Zhang L, Chen HL (2010) Enhanced lipid production of Chlorella 527 vulgaris by adjustment of cultivation conditions. Bioresource Technol 1016797-6804

528 Mata TM, Martins AA, Caetano NS (2010) Microalgae for biodiesel production and other 529 applications: a review. Renew Sust Energ Rev 14:217-232

530 Marsalek J, Marsalek PM (1997) Characteristics of sediments from a stormwater management 531 pond. Wat Sci Technol 36:117-22

532 Nascimento IA, Marques SSI, Cabanelas ITD, Pereira SA, Druzian JI, de Souza CO, Vich DV, 533 de Carvalho GC, Nascimento MA (2013) Screening microalgae strains for biodiesel

534 production: lipid productivity and estimation of fuel quality based on fatty acids profiles as 535 selective criteria. BioEnerg Res 6:1-13

536 O'Fallon JV, Busboom JR, Nelson ML, Gasakins CT (2007) A direct method for fatty acid 537 methyl ester synthesis: Application to wet meat tissues, oils, and feedstuffs. J Anim Sci 
539 Pittman JK, Dean AP, Osundeko O (2011) The potential of sustainable algal biofuel production $540 \quad$ using wastewater resources, Bioresource Technol 102:17-25

541 Principi P, Villa F, Bernasconi M, Zanardini E (2006) Metal toxicity in municipal wastewater 542 activated sludge investigated by multivariate analysis and in situ hybridization. Wat Res 40 : $54399-106$.

544 Ramos MJ, Fernández CM, Casas A, Rodríguez L, Pérez Á (2009) Influence of fatty acid 545 composition of raw materials on biodiesel properties. Bioresource Technol 100:261-8

546 Rippka R, Deruelles J, Waterbury J, Herdman M, Stanier R (1979) Generic assignments, strain

547 histories and properties of pure cultures of cyanobacteria. J Gen Microbiol 111:1-61

548 Ruiz-Marin A, Mendoza-Espinosa LG, Stephenson T (2010) Growth and nutrient removal in free 549 and immobilized green algae in batch and semi-continuous cultures treating real wastewater. $550 \quad$ Bioresour Technol 101:58-64

551 Saitou N, Nei M (1987) The neighbor-joining method: A new method for reconstructing 552 phylogenetic trees. Mol Biol Evol 4:406-425

553 Schenk PM, Thomaas-Hall SR, Steohens E, Marx UC, Mussging JH, Posten C, Kruse O, 554 Hankamer B (2008) Second generation biofuels: High-efficiency microalgae for biodiesel 555 production. BioEnerg Res 1:20-43

556 Sforza E, Simionato D, Giacometti GM, Bertucco A, Morosinotto T (2012) Adjusted light and 557 dark cycles can optimize photosynthetic efficiency in algae growing in photobioreactors. $558 \quad$ PloS One doi: 10.1371/journal.pone.0038975

559 Sharif Hossain ABM, Salleh A, Boyce AN, Chowdhury P, Naqiuddin M (2008) Biodiesel fuel 560 production from algae as renewable energy. Am J Biochem Biotechnol 4:250-254 
561 Sheath RG, Wehr JD (2003) Freshwater algae of North America: ecology and classification.

562 Academic Press, USA

563 Stein JR, Hellebust JA, Craigie JS (1973) Handbook of phycological methods: physiological and 564 biochemical methods (Vol. 2). Cambridge University Press, Cambridge, UK

565 Stemmler K, Massimi R and Kirkwood AE (2016) Growth and fatty acid characterization of 566 microalgae isolated from municipal waste-treatment systems and the potential role of algal567 associated bacteria in feedstock production. PeerJ, 4, p.e1780.

568 Tam NFY, Wong YS (1990) The comparison of growth and nutrient removal efficiency of 569 Chlorella pyrenoidosa in settled and activated sewages. Environ Pollut 65:93-108 570 Tam NFY, Wong YS (1989) Wastewater nutrient removal by Chlorella pyrenoidosa and $571 \quad$ Scenedesmus sp. Environ Pollut 58:19-34

572 Vilgalys R (2003) Taxonomic misidentification in public DNA databases. New Phytol 160:4-5

573 Vincent J, Kirkwood AE (2014) Variability of water quality, metals and phytoplankton 574 community structure in urban stormwater ponds along a vegetation gradient. Urban Ecosyst $575 \quad 17: 839-853$

576 Wang $\mathrm{C}, \mathrm{Hu} \mathrm{X}$, Chen ML, Wu YH (2005) Total concentrations and fractions of $\mathrm{Cd}, \mathrm{Cr}, \mathrm{Pb}, \mathrm{Cu}$, $577 \quad \mathrm{Ni}$ and $\mathrm{Zn}$ in sewage sludge from municipal and industrial wastewater treatment plants. J 578 Hazard Mater 119:245-249

579 White TJ, Bruns T, Lee S, Taylor J (1990) Amplification and direct sequencing of fungal 580 ribosomal RNA genes for phylogenetics. In: Innis MA, Gelfand DH, Sninsky JJ, White TJ 581 (eds) PCR Protocols: A Guide to Methods and Applications. Academic Press, San Diego, pp. $582 \quad 315-22$

583 Woertz I, Feffer A, Lundquist T, Nelson Y (2009) Algae grown on dairy and municipal 
584 wastewater for simultaneous nutrient removal and lipid production for biofuel feedstock. J $585 \quad$ Environ Eng 135:1115-1122

586 Yang J, Xu M, Zhang X, Qiang Hu, Sommerfield M, Chen Y (2011) Life-cycle analysis on 587 biodiesel production from microalgae: Water footprint and nutrients balance. Bioresource $588 \quad$ Technol 102:159-165

589 Zhou W, Li Y, Min M, Hu B, Chen P, Ruan R (2011) Local bioprospecting for high-lipid 590 producing microalgal strains to be grown on concentrated municipal wastewater for biofuel 591 production. Bioresource Technol 102:6909-6919 


\section{Table $\mathbf{1}$ (on next page)}

Summary list of isolated strains.

Summary list of isolated strains and their associated isolation medium, source location, tentative taxonomic assignment and 18S rRNA sequence similarity with BLAST taxa. Growth rate and generation time under standardized growth conditions over 7-days are also included. With the exception of one cyanobacterial strain (Microcystis sp.) which has been listed because of its inclusion in the bioassay results, all eukaryotic strains were subjected to $18 \mathrm{~S}$ rRNA sequencing using NS1 and ITS2/18L primers. NS = Strain not successfully sequenced, WWTP $=$ Wastewater Treatment Plant, SWP $=$ Stormwater Pond, RP $=$ Reference Pond, Lake ON = Lake Ontario. See Vincent and Kirkwood (2014) for more information on stormwater and reference pond characteristics. 
Table 1. Summary list of isolated strains and their associated isolation medium, source location, tentative taxonomic assignment and 18S rRNA sequence similarity with BLAST taxa. Growth rate and generation time under standardized growth conditions over 7-days are also included. With the exception of one cyanobacterial strain (Microcystis sp.) which has been listed because of its inclusion in the bioassay results, all eukaryotic strains were subjected to 18S rRNA sequencing using NS1 and ITS2/18L primers. NS $=$ Strain not successfully sequenced, WWTP $=$ Wastewater Treatment Plant, SWP $=$ Stormwater Pond, RP = Reference Pond, Lake ON = Lake Ontario. See Vincent and Kirkwood (2014) for more information on stormwater and reference pond characteristics.

\begin{tabular}{|c|c|c|c|c|c|c|c|c|}
\hline Strain ID & $\begin{array}{l}\text { Isolating } \\
\text { Medium }\end{array}$ & $\begin{array}{l}\text { Source } \\
\text { Location } \\
\end{array}$ & Taxonomic Assignment & Closest BLAST Match & $\begin{array}{c}\text { Similarity } \\
(\%)\end{array}$ & $\begin{array}{c}\text { Sequence } \\
\text { Size } \\
\text { (bp) } \\
\end{array}$ & $\begin{array}{c}\text { Growth } \\
\text { Rate } \\
\left(d^{-1}\right) \\
\end{array}$ & $\begin{array}{c}\text { Generation } \\
\text { Time } \\
\text { (hrs) }\end{array}$ \\
\hline $\mathrm{Sp} 1.41$ & CHU10 & SWP 1 & Scenedesmus sp. & Desmodesmus armatus KF673362 & 99 & 1160 & 1.14 & 14.6 \\
\hline Sp 1.43 & CHU10 & SWP 1 & Desmodesmus sp. & Desmodesmus intermedius FR865701 & 98 & 1253 & 0.74 & 21.1 \\
\hline $\mathrm{Sp} 1.44$ & CHU10 & SWP 1 & Chlorella sp. & Chlorella sp. KP262476 & 99 & 1580 & 0.75 & 22.2 \\
\hline Sp1.46 & CHU10 & SWP 1 & Dictyosophaerium sp. & Dictyosphaerium ehrenbergianum GQ487213 & 99 & 474 & 0.69 & 24.0 \\
\hline Sp1.50 & CHU10 & SWP 1 & Ankistrodesmus sp. & Ankistrodesmus gracilis. AB917098 & 98 & 1618 & 1.15 & 14.5 \\
\hline Sp1.52 & CHU10 & SWP 1 & Chlorella sp. & Mychonastes rotundus GQ477053 & 83 & 343 & 0.97 & 17.2 \\
\hline Sp11.30 & CHU10 & SWP 11 & Scenedesmus sp. & Scenedesmus obliquus FN298925 & 99 & 911 & 0.51 & 32.6 \\
\hline Sp12.07 & BG11 & SWP 12 & Chlorella sp. & Coelastrum astroideum GQ375093 & 99 & 1518 & 0.55 & 30.2 \\
\hline Sp12.21 & CHU10 & SWP 12 & Chlorella sp. & Coelastrum astroideum GQ375093 & 100 & 850 & 1.04 & 16.1 \\
\hline Sp12.36 & CHU10 & SWP 12 & Scenedesmus sp. & Acutodesmus obliquus AB917101 & 99 & 1614 & 0.90 & 18.6 \\
\hline Sp13.17 & CHU10 & SWP 13 & Chlorella sp. & Mychonastes huancayensi GQ477050 & 100 & 1445 & 0.99 & 17.7 \\
\hline Sp14.35 & CHU10 & SWP 14 & Selenastrum sp. & NS & -- & -- & 0.96 & 17.41 \\
\hline Sp16.26 & CHU10 & SWP 16 & Scenedesumus sp. & Scenedesmus sp. FN298925 & 99 & 1431 & 0.90 & 18.6 \\
\hline Sp16.34 & CHU10 & SWP 16 & Scenedesmus sp. & Scenedesmus obliquus KJ676128 & 99 & 714 & 1.10 & 15.1 \\
\hline SpU.9* & CHU10 & SWP 16 & Chlamydomonas sp. & Chlamydomonas inflexa FR865584 & 97 & 1143 & 0.59 & 28.1 \\
\hline Sp17.013 & BG11 & SWP 17 & Monoraphidium sp. & Monoraphidium convolutum HM483515 & 99 & 1309 & 0.92 & 18.1 \\
\hline Sp17.022 & BG11 & SWP 17 & Chlorococcum sp. & Chlorococcum ellipsoideum U70586 & 95 & 423 & 0.65 & 25.6 \\
\hline
\end{tabular}




\begin{tabular}{|c|c|c|c|c|c|c|c|c|}
\hline Sp17.25 & CHU10 & SWP 17 & Chlorella sp. & Chlorella luteoviridis FR865678 & 99 & 1482 & 0.98 & 17.0 \\
\hline Sp17.38 & CHU10 & SWP 17 & Monoraphidium sp. & Monoraphiridium sp. JN187941 & 98 & 873 & 1.12 & 14.9 \\
\hline Sp19.010 & BG11 & SWP 19 & Desmodesmus sp. & Desmodesmus communis KF864475 & 99 & 1178 & 0.64 & 26.0 \\
\hline Sp19.011 & BG11 & SWP 19 & Scenedesmus sp. & Scenedesmus acuminatus AB037088 & 99 & 1073 & 1.24 & 13.5 \\
\hline Sp19.015 & CHU10 & SWP 19 & Monoraphidium sp & Monoraphiridium contortum AY846382 & 97 & 588 & 0.72 & 23.1 \\
\hline Sp19.15 & CHU10 & SWP 19 & Desmodesmus sp. & Desmodesmus pannonicus FR865712 & 98 & 821 & 1.22 & 13.7 \\
\hline Sp19.40 & CHU10 & SWP 19 & Chlamydomonas sp. & Chlamydomonas debaryana JN903975 & 99 & 651 & 1.10 & 15.1 \\
\hline Sp21.01 & BG11 & SWP 21 & Microcystis sp. & -- & -- & -- & 0.69 & 24.0 \\
\hline $\mathrm{Sp} 21.02$ & BG11 & SWP 21 & Chlorella sp. & Chlorella luteoviridis FR865678 & 99 & 718 & 0.80 & 20.7 \\
\hline Sp21.12 & CHU10 & SWP 21 & Scenedesmus sp. & Scenedesmus sp. FR865732 & 99 & 1483 & 0.40 & 41.8 \\
\hline Sp21.14 & CHU10 & SWP 21 & Chlorella sp. & Chlorella luteoviridis FR865678 & 99 & 449 & 0.75 & 22.1 \\
\hline $\mathrm{Sp} 21.20$ & CHU10 & SWP 21 & Chlorella sp. & Chlorella luteoviridis FR865678 & 100 & 1336 & 0.42 & 39.8 \\
\hline Sp21.37 & CHU10 & SWP 21 & Ankistrodesmus sp. & Monoraphidium contortum KM067465 & 94 & 626 & 1.10 & 15.1 \\
\hline Sp21.23 & CHU10 & SWP 21 & Desmodesmus sp. & Desmodesmus intermedius FR865701 & 99 & 1245 & 1.07 & 15.6 \\
\hline Sp23.13 & CHU10 & RP 23 & Chlorella sp. & Micractinium inermum KF597304 & 100 & 1005 & 0.55 & 30.3 \\
\hline $\mathrm{Sp} 24.1$ & CHU10 & RP 24 & Scenedesmussp. & Scenedesmus sp. FN298925 & 100 & 257 & 0.55 & 30.3 \\
\hline Sp24.05 & BG11 & RP 24 & Desmodesmus sp. & Desmodesmus pannonicus FR865712 & 99 & 1158 & 0.50 & 33.2 \\
\hline LO47 & CHU10 & Lake ON & Ankistrodesmus sp. & Monoraphidium griffthii. AY846383 & 100 & 1454 & 0.74 & 22.5 \\
\hline LO48 & CHU10 & Lake ON & Scenedesmus sp. & Scenedesmus obliquus FR865738 & 100 & 1119 & 1.00 & 16.7 \\
\hline LO49 & CHU10 & Lake ON & Chlorella sp. & Micractinium sp. AB9187105 & 100 & 350 & 1.08 & 22.2 \\
\hline LO51 & CHU10 & Lake ON & Chlorella sp. & Chlorella luteoviridis. FR865678 & 100 & 585 & 0.58 & 29.1 \\
\hline WW3 & CHU10 & WWTP & Chlorella sp. & Coelastrum microporum JQ315528 & 98 & 497 & 0.63 & 25.3 \\
\hline WW5 & CHU10 & WWTP & Scenedesmus sp. & Acutodesmus obliquus KF144164 & 99 & 597 & 0.58 & 28.7 \\
\hline WW8 & CHU10 & WWTP & Chlorella sp. & Chlorella luteoviridis. FR865678 & 99 & 761 & 0.80 & 20.7 \\
\hline WW27 & CHU 10 & WWTP & Chlorella sp. & Chlorella luteoviridis FR865678 & 99 & 1304 & 0.77 & 21.7 \\
\hline WW39 & CHU10 & WWTP & Desmodesmus sp. & Desmodesmus intermedius KF673371 & 99 & 1572 & 0.66 & 25.4 \\
\hline
\end{tabular}

$9{ }^{*}$ The source location for strain SpU.9 is either SWP 16 or SWP 17. 


\section{Table 2 (on next page)}

Biodiesel properties of algal isolates.

Biodiesel properties of algal isolates based on their fatty acid profiles. The ASTM Biodiesel Standard D675 requirement for Cetane Number is a minimum value $=47$ and lodine Value maximum $=120$. Degree of Unsaturation is a weighted sum of the masses of monounsaturated and polyunsaturated fatty acids, and Long-Chain Saturation Factor is a weighted sum of long-chain fatty acids (C16, C18, C20, C22 and C24). Saponification value is equivalent to milligrams of potassium hydroxide required to saponify $1 \mathrm{~g}$ of oil. 
Table 2. Biodiesel properties of algal isolates based on their fatty acid profiles. The ASTM Biodiesel Standard D675 requirement for Cetane Number is a minimum value $=47$ and Iodine Value maximum $=120$. Degree of Unsaturation is a weighted sum of the masses of monounsaturated and polyunsaturated fatty acids, and Long-Chain Saturation Factor is a weighted sum of long-chain fatty acids (C16, C18, C20, C22 and C24). Saponification value is equivalent to milligrams of potassium hydroxide required to saponify $1 \mathrm{~g}$ of oil.

\begin{tabular}{|c|c|c|c|c|c|c|}
\hline Strain ID & $\begin{array}{c}\text { Cetane } \\
\text { Number }\end{array}$ & $\begin{array}{l}\text { Iodine } \\
\text { Value }\end{array}$ & $\begin{array}{c}\text { Degree of } \\
\text { Unsaturation } \\
(w t \%) \\
\end{array}$ & $\begin{array}{c}\text { Long-Chain } \\
\text { Saturation Factor } \\
(w \mathrm{w} \%) \\
\end{array}$ & $\begin{array}{c}\text { Saponification } \\
\text { Value } \\
\text { (mg) } \\
\end{array}$ & $\begin{array}{c}\text { Cold Filter } \\
\text { Plugging Point } \\
\left({ }^{\circ} \mathrm{C}\right) \\
\end{array}$ \\
\hline Sp1.41 & 59.4 & 51.9 & 57.7 & 4.44 & 207 & -3 \\
\hline Sp1.43 & 61.0 & 45.0 & 50 & 5.12 & 209 & 0 \\
\hline Sp1.44 & 53.7 & 74.3 & 66.9 & 4.9 & 207 & -1 \\
\hline Sp1.46 & 58.0 & 56.3 & 62.5 & 4.01 & 210 & -4 \\
\hline Sp1.50 & 18.9 & 207 & 120 & 2.37 & 215 & -9 \\
\hline Sp1.52 & 55.4 & 67.0 & 60.4 & 4.51 & 209 & -2 \\
\hline Sp12.07 & 44.6 & 108 & 76.7 & 4.11 & 211 & -4 \\
\hline $\mathrm{Sp} 12.21$ & 57.4 & 59.7 & 56.6 & 4.1 & 207 & -4 \\
\hline Sp12.36 & 55.3 & 68.7 & 68.6 & 3.45 & 206 & -6 \\
\hline Sp14.35 & 60.3 & 48.3 & 53.7 & 4.69 & 208 & -2 \\
\hline Sp16.26 & 59.1 & 53.7 & 59.8 & 4.02 & 206 & -4 \\
\hline Sp16.34 & 45.6 & 110 & 104 & 0.55 & 200 & -15 \\
\hline SpU9 & 65.6 & 13.3 & 37.3 & 8.26 & 241 & 9 \\
\hline Sp17.013 & 36.3 & 139 & 85.7 & 4.16 & 214 & -3 \\
\hline Sp17.022 & 66.0 & 22.7 & 46.1 & 6.44 & 214 & 4 \\
\hline Sp17.25 & 61.3 & 42.9 & 47.6 & 6.02 & 210 & 2 \\
\hline Sp19.010 & 55.0 & 68.0 & 60.5 & 4.4 & 210 & -3 \\
\hline Sp19.011 & 54.7 & 68.0 & 57.7 & 4.59 & 212 & -2 \\
\hline Sp19.15 & 56.4 & 63.2 & 59.8 & 4.43 & 208 & -3 \\
\hline Sp19.40 & 68.8 & 10.7 & 11.9 & 8.81 & 216 & 11 \\
\hline
\end{tabular}




\begin{tabular}{lcccccc} 
Sp21.02 & 25.3 & 186 & 118 & 3.51 & 206 & -5 \\
Sp21.12 & 58.1 & 56.6 & 56.6 & 4.71 & 208 & -2 \\
Sp21.14 & 55.0 & 68.5 & 62 & 5.15 & 208 & 0 \\
Sp21.20 & 53.9 & 71.9 & 60 & 5.76 & 210 & 2 \\
Sp21.37 & 60.7 & 46.5 & 51.7 & 4.83 & 208 & -1 \\
Sp23.13 & 69.1 & 9.60 & 10.6 & 8.94 & 216 & 12 \\
Sp24.05 & 47.7 & 94.8 & 69 & 4.18 & 215 & -3 \\
LO47 & 56.1 & 61.1 & 42 & 7.24 & 206 & -6 \\
LO48 & 53.9 & 73.9 & 71.3 & 3.44 & 207 & 0 \\
LO49 & 52.6 & 78.6 & 66.2 & 5.15 & 217 & 5 \\
LO51 & 67.8 & 14.5 & 48.8 & 6.88 & 207 & -8 \\
WW3 & 53.9 & 73.5 & 73.1 & 2.67 & 203 & -12 \\
WW39 & 49.5 & 93.0 & 90.6 & 1.45 & 210 & -10 \\
WW5 & 31.0 & 162 & 35.2 & 2.01 & & \\
\hline
\end{tabular}




\section{Table 3 (on next page)}

Comparison of algal tolerance to copper.

Comparison of algal tolerance to the range of copper concentrations typically found in municipal-wastewater systems (Environment Canada 2001). Copper concentrations previously measured for source stormwater-ponds are also included (Vincent and Kirkwood 2014). Average percent-inhibition is reported for each test concentration: N/A = information not available. 
1 Table 3. Comparison of algal tolerance to the range of copper concentrations typically found in municipal-wastewater systems (Environment Canada 2001). Copper concentrations previously measured for source stormwater-ponds are also included (Vincent and Kirkwood 2014). Average percent-inhibition is reported for each test concentration: N/A = information not available.

\begin{tabular}{lccc} 
& & \multicolumn{2}{c}{ Copper (\% Inhibition) } \\
\cline { 3 - 4 } Strain ID & $\begin{array}{c}\text { Source Location } \\
\text { Copper }\left(\mathbf{m g} \cdot \mathbf{L}^{-1}\right)\end{array}$ & $\mathbf{0 . 0 1} \mathbf{~ m g} \cdot \mathbf{L}^{-\mathbf{1}}$ & $\mathbf{0 . 1} \mathbf{~ m g} \cdot \mathbf{L}^{-\mathbf{1}}$ \\
\hline Chlorella kesslerii CPCC266 & N/A & 0 & 0 \\
Chlorella sp. Sp21.20 & 0.0021 & 5.25 & 5.84 \\
Scenedesmus sp. Sp11.30 & 0.0035 & 0 & 0 \\
Selenatrum sp. Sp14.35 & 0.0061 & 0 & 1.04 \\
Monoraphidium sp. Sp17.38 & 0.0040 & 0 & 0.22 \\
Microcystis sp. Sp21.01 & 0.0021 & 0.86 & 53.4 \\
\hline
\end{tabular}


Figure 1 (on next page)

Unrooted Neighbor-joining tree for 18S rRNA NS1-region sequences

Unrooted Neighbor-joining tree for $18 \mathrm{~S}$ rRNA NS1-region sequences greater than $400 \mathrm{bp}$ for algal isolates and related taxa from the NCBI database. Bootstrap scores are based on 1000 replicates. NCBI database accession-codes have been included with strain names. 


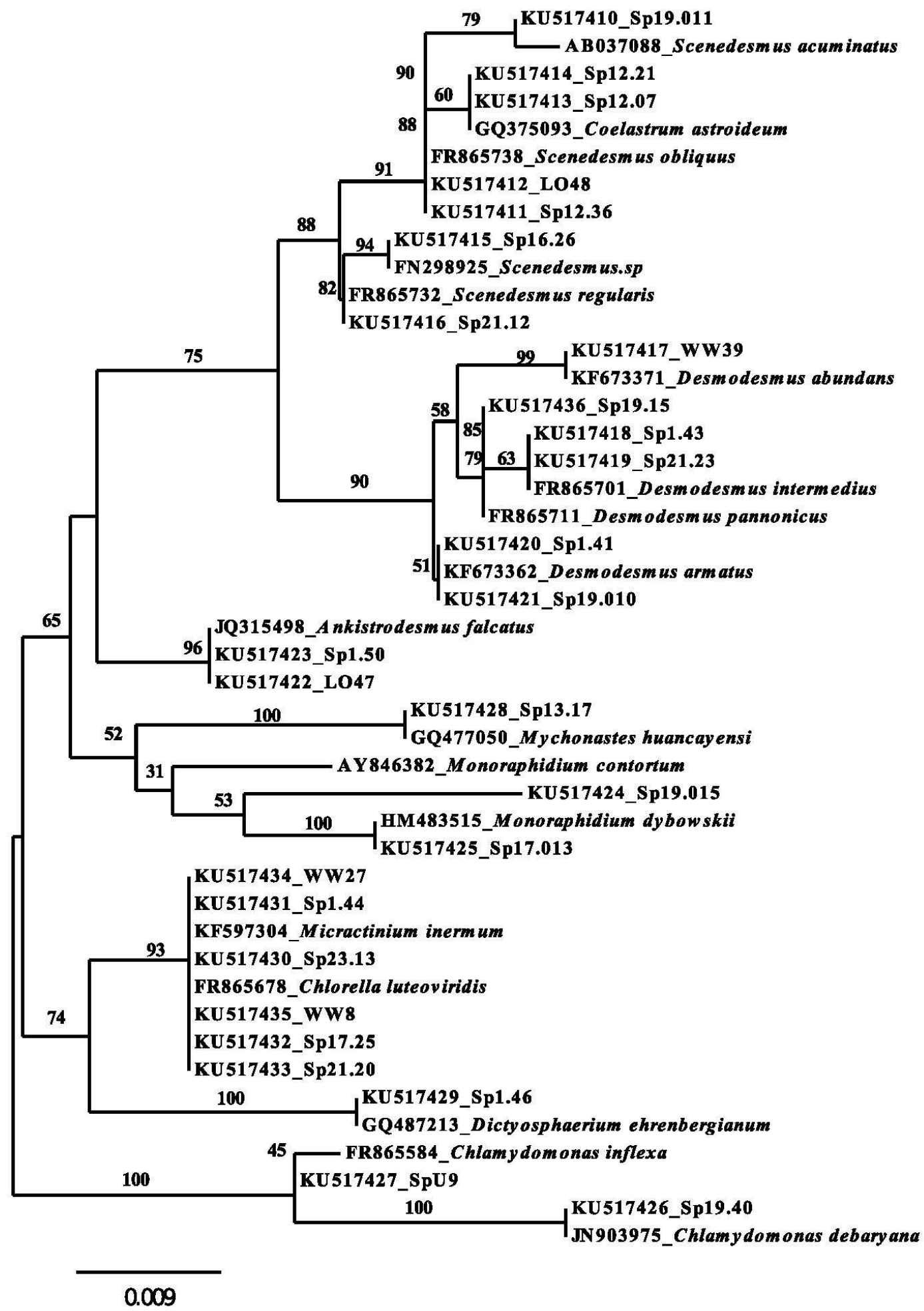

Fig. 1 


\section{Figure 2 (on next page)}

\section{FAME Profiles}

FAME profiles for thirty-four axenic algal isolates based on the relative abundance of fatty acids detected by GC-MS. 


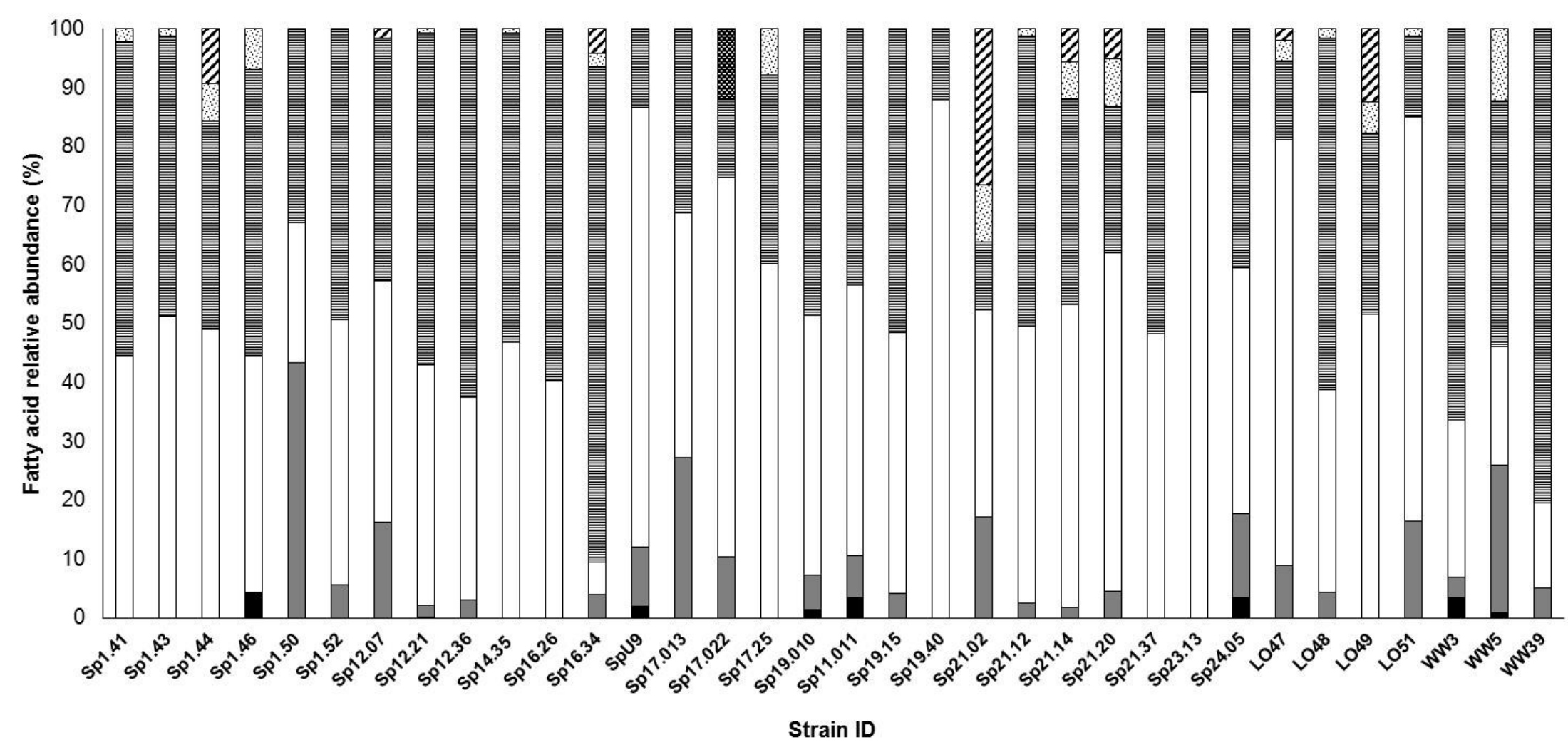

- Lauric acid ME (C12:0)

口Palmitic acid ME (C16:0)

圆Oleic acid ME trans (C18:1)

$\varangle 8,11,14,17$ Eicsoatetraenoic acid ME (C20:4(n-3))

$\square 4,7,10,13$ Hexadecatraenoate ME (C16:4(n-3)

目Oleic acid ME (C18:1)

: Linoleic acid ME (18:2)

Fig. 2 
Figure 3 (on next page)

Comparison of FAME profiles among phylotytypes.

Comparison of FAME profiles among distinct phylotypes with 2 or more isolated strains using Bray-Curtis Unweighted Pair Group Method with Arithmetic Mean (UPGMA) cluster analysis. Strains of the same phylotype appear as the same colour in the dendrogram 


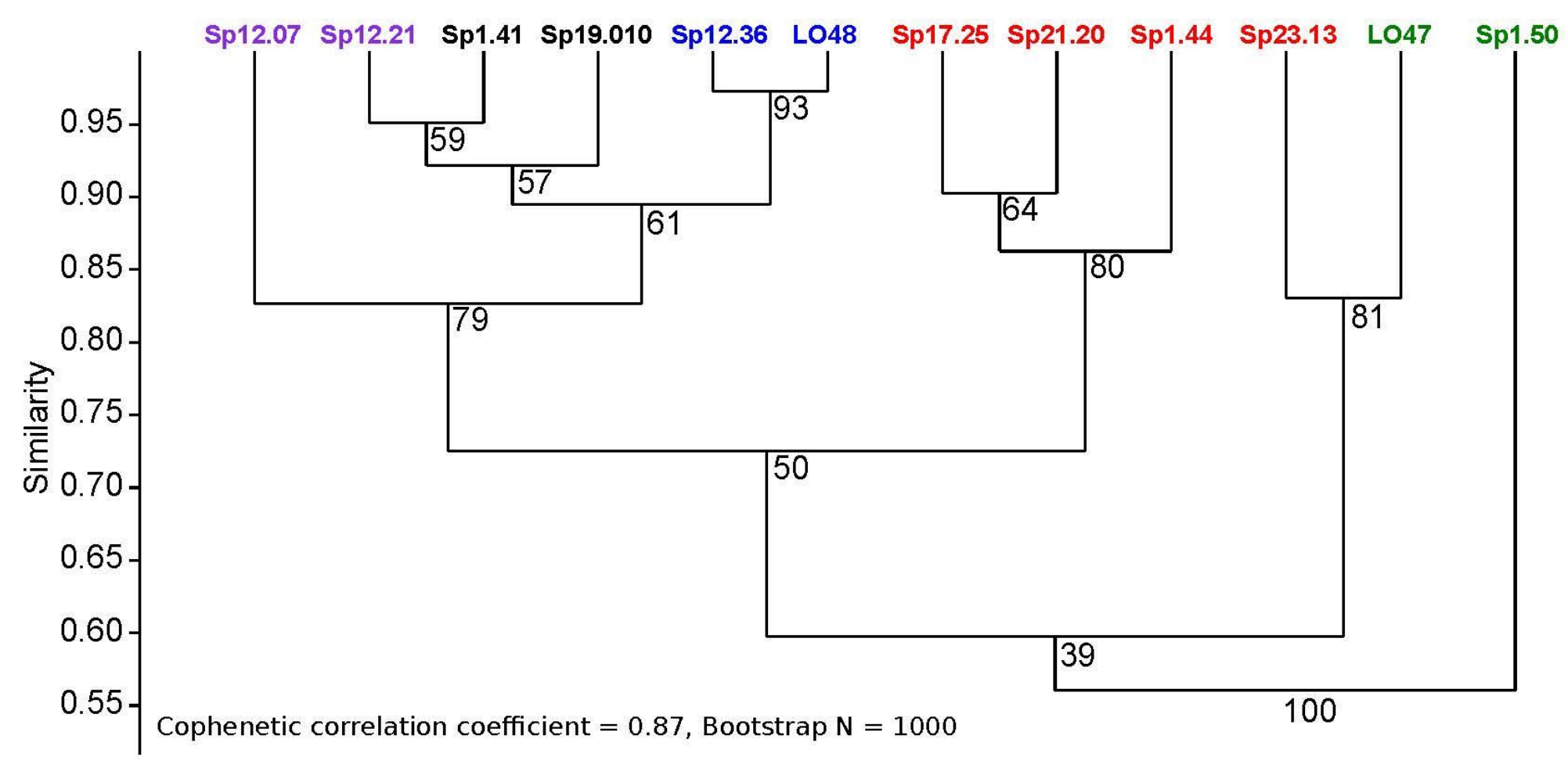

Fig. 3 